\title{
Análise comparativa de resultados de ensaios de compressão triaxial com corpos de prova de diferentes dimensões
}

\author{
Comparative analysis of triaxial compression test results with \\ different dimensions proof bodies
}

\author{
Ícaro Rodrigues Marques \\ icarormarques@hotmail.com \\ Universidade de Fortaleza \\ Instituto Federal do Ceará \\ Fernando Feitosa Monteiro \\ fernandofm91@hotmail.com \\ Universidade Federal do \\ Ceará \\ Marco Fabio Porto de \\ Aguiar \\ marcosfpa@hotmail.com \\ Universidade de Fortaleza \\ Instituto Federal do Ceará \\ Francisco Heber Lacerda \\ de Oliveira \\ heberoliveiracivil@hotmail. \\ com \\ Universidade de Fortaleza
}

\begin{abstract}
Resumo
Este trabalho visa, por meio da utilização do ensaio de compressão triaxial, comparar resultados obtidos com a utilização de corpos de prova com dimensões de 2" e 1,4" de diâmetros. Optouse por condição de ensaio adensado não drenado (CIU), sendo o equipamento com deformação controlada. O estudo analisou as envoltórias de Mohr-Coulomb totais e efetivas, caminho de tensões e poropressões obtidas para os corpos de prova de 2" e 1,4", utilizando-se amostras de solo areno argilosas bem graduadas. Verificou-se que os corpos de prova de maior dimensão apresentaram ângulos de atrito e de ruptura, semelhantes aos de menor dimensão, porém, encontra-se uma variação nos valores de coesão, total e efetiva. Entretanto, pode-se ressaltar a maior dificuldade na realização do ensaio com o corpo de $1,4^{\prime \prime}$.
\end{abstract}

Palavras-chave: Ensaio de compressão Triaxial. CIU. Cisalhamento. Diâmetro.

\begin{abstract}
This article aims the usage of the triaxial compression test, comparing the results that were obtained using the test specimen with dimensions of 2 " and 1,4" diameter. It was chosen for condition consolidated undrained test (CIU) the device being strain-controlled. The study examined the envelopes of total and effective Mohr-Coulomb stress path and pore pressure obtained for the samples of 2" and 1.4", using clay sandy soil samples and graded. It was found that the larger specimens exhibited angles of friction and breakage, similar to the smaller, but there is a variation in the cohesion values of total and effective. However it can be seen more difficulty in performing the test on the specimen of 1.4 ".
\end{abstract}

Keywords: Compression Test Triaxial. CIU. Shear. Diameter.

\section{Introdução}

O ensaio de compressão triaxial é muito utilizado internacionalmente quando se trata da resistência ao cisalhamento dos solos e da obtenção de seus parâmetros, porém, ainda é pouco utilizado no Brasil.

Conforme Pinto (2006), o ensaio consiste na aplicação de um estado hidrostático de tensões e de um carregamento axial sobre um corpo de prova cilíndrico de solo. O ensaio nos fornece diversas possibilidades de condições, e seus procedimentos podem ser relacionados aos diversos problemas práticos. Dessa forma, a ênfase deste artigo consiste em analisar os resultados obtidos através de ensaios de compressão triaxial de diferentes corpos de provas - no caso, de 1,4" e 2" de diâmetro, verificando se há diferença significativa entre os resultados encontrados, com ênfase nos parâmetros efetivos de resistência. 


\section{Fundamentação Teórica}

Neste item, serão abordados alguns conceitos necessários para a compreensão do ensaio e dos resultados encontrados.

\subsection{Princípio das pressões efetivas de Terzaghi}

Terzaghi (1936) identificou, a partir do estudo da natureza de diferentes forças atuantes, que a tensão normal total $(\sigma)$ é a soma de duas parcelas: a tensão transmitida pelos contatos entre as partículas, denominada tensão efetiva $(\sigma ')$, e pela pressão da água, denominada poropressão ou pressão neutra $(u)$.

Logo, o princípio das pressões efetivas estabelecido por Terzaghi pode ser expresso em duas partes:

1) A tensão efetiva para solos saturados pode ser expressa como segue:

$\sigma=\sigma^{\prime}+\mathrm{u}$

2) Todos os efeitos mensuráveis resultantes de variações de tensões nos solos, como compressão, distorção e resistência ao cisalhamento, são devido à variação de tensões efetivas.

\subsection{Tensões Principais}

Qualquer ponto no interior do maciço terroso está sujeito a esforços internos, provenientes do seu peso próprio, e àqueles gerados por forças externas. Esses esforços podem ser representados pelas suas resultantes atuantes nas direções normal e tangencial, as quais definem o estado de tensão normal $(\sigma)$ e cisalhante $(\tau)$.

Quando se aplica esse conceito a uma condição tridimensional, obtém-se o estado triplo de tensões, que é o estado de tensão do maciço terroso em torno de um ponto qualquer, representado quando se conhece as tensões atuantes em três planos que formam o triedro triangular (CAPUTO, 1988) - condição tridimensional representada na Figura 1.

Figura 1: Plano de tensões componentes tridimensionais positivos (GERSCOVICH, 2012)

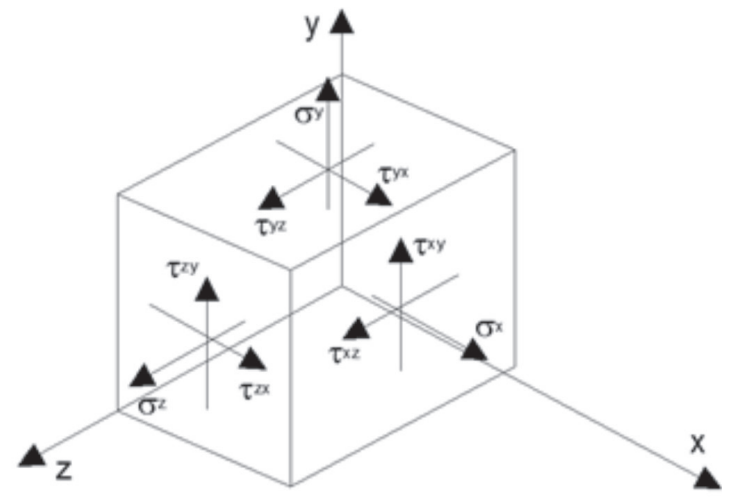

A partir da obtenção das tensões, pode-se determinar a tensão principal, definida como a tensão normal sobre um plano em que não há tensão de cisalhamento (CUPOTO, 1988), isto é, planos ortogonais entre si, definidos por um sistema de eixos cartesianos. Em cada um, a tensão atuante é a tensão normal (), devido à tensão cisalhante (ser nula. As tensões principais maior, menor e intermediária são denominadas respectivamente de $\sigma_{1}, \sigma_{3}$ e $\sigma_{2}$.

Em casos especiais:

1) Devido às características de geometria dos maciços terrosos, há problemas que podem ser simplificados quanto ao tratamento do estado de tensão e deformação, considerando apenas $\sigma_{1}$ e $\sigma_{3}$, obtendo situações interpretadas no plano. O estado "plano de deformação" apresentará valores insignificantes ou nulos em uma das direções quando comparados aos valores nas demais direções, tendo todas as deformações em um plano transversal. Podem-se citar como exemplo as barragens, rodovias e muros longos.

2) Pode-se considerar também $\sigma_{2}=\sigma_{3}$ quando houver condição axissimétrica, que ocorre quando há a presença de um eixo de simetria axial (ORTIGÃO, 2007). Podem-se citar como exemplos estacas de seção circular e o ensaio de compressão triaxial, em que uma amostra cilíndrica é imposta à compressão e variam-se as tensões radial e axial. O nome 
dado ao ensaio é inapropriado, pois as condições impostas à amostra são axissimétricas, e não triaxiais verdadeiras. A situação axissimétirca é exemplificada na Figura 2.

Figura 2: Situação axissimétrica em um corpo-de-prova (GERSCOVICH, 2010)

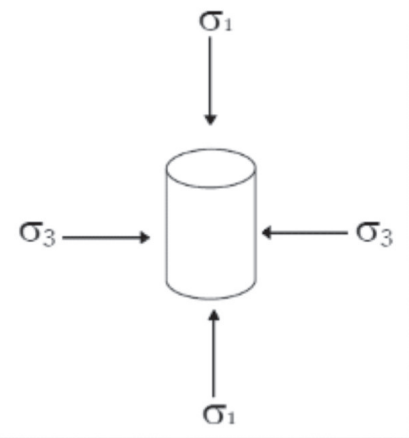

Em um plano de deformação, quando se conhece o estado de tensões principais num ponto qualquer, pode-se determinar as tensões em qualquer plano que passe por esse ponto (Figura 3).

Figura 3: Tensões no plano inclinado (PINTO, 2006)

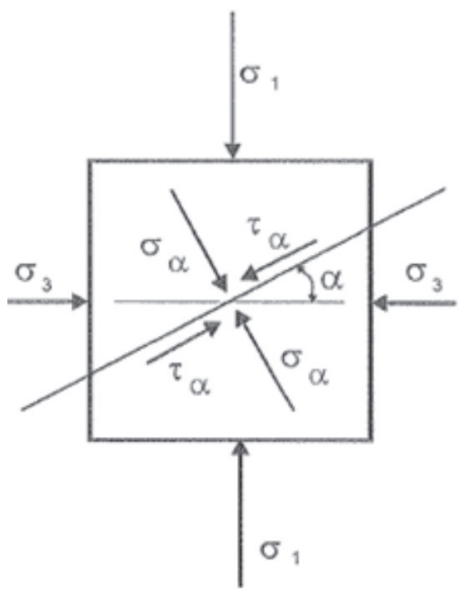

Com as equações de equilíbrio dos esforços aplicados a um prisma triangular definido por dois planos principais e o plano considerado, obtém-se expressões que indicam as tensões normal e cisalhante, em função das tensões principais $\sigma_{1}$ e $\sigma_{3}$, e do ângulo, $\alpha$, que o plano considerado determina com o plano principal maior.

$$
\begin{aligned}
& \sigma=\frac{\sigma_{1}+\sigma_{3}}{2}+\frac{\sigma_{1}-\sigma_{3}}{2} \cdot \cos 2 \alpha \\
& \tau=\frac{\sigma_{1}-\sigma_{3}}{2} \cdot \sin 2 \alpha
\end{aligned}
$$

\subsection{Círculos de Mohr}

O círculo de Mohr é uma figura geométrica construída num sistema de coordenadas $(\sigma ; \tau)$ que representa graficamente o estado de tensões atuantes, $\left(\sigma_{\alpha} ; \tau_{\alpha}\right)$ em todos os planos, passando por um ponto. Pode ser obtido a partir da tensão normal e cisalhante, e de posse de duas tensões principais, como exemplificado na Figura 4. 
Figura 4: Círculo de Mohr (CAPUTO, 1988)

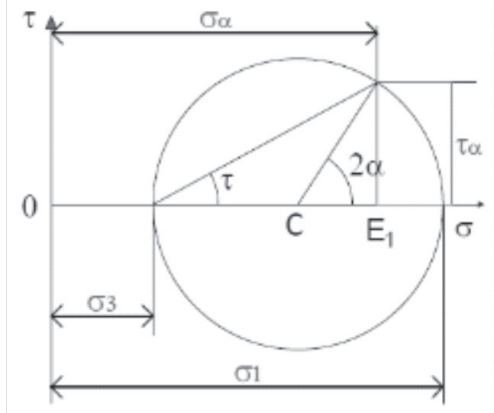

Utilizando o círculo de Mohr, pode-se representar e interpretar resultados de ensaios de resistência ao cisalhamento dos solos em condição axissimétrica, como no caso de ensaios de compressão triaxial.

\subsection{Estados de tensões efetivas}

O estado de tensões pode ser definido tanto em termos de tensões totais como de tensões efetivas. Considerando-se as tensões principais $\sigma_{1}, \sigma_{3}$ e a pressão neutra (u) no solo. Os dois círculos de Mohr, indicados na Figura 5, podem ser construídos. Com base na Figura 5, podemos destacar dois pontos:

a) O círculo de tensões efetivas se encontra deslocado para a esquerda em relação ao círculo de tensões totais, de um valor igual à pressão neutra. Tal fato é decorrente de a pressão neutra atuar hidrostaticamente, reduzindo a igual valor as tensões normais em todos os planos. No caso de pressões neutras negativas, o deslocamento do círculo é, pela mesma razão, para a direita.

b) As tensões de cisalhamento em qualquer plano são independentes da pressão neutra, pois a água não transmite esforços de cisalhamento. As tensões de cisalhamento são devido à diferença entre as tensões principais, e essa diferença é a mesma, tanto em tensões totais como em tensões efetivas (PINTO, 2006).

Figura 5: Efeito da pressão neutra no estado de tensões em um elemento de solo (PINTO, 2006)

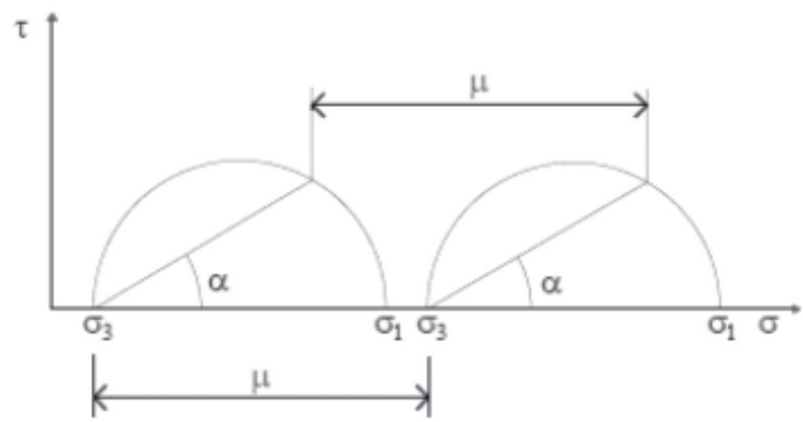

\subsection{Resistências ao cisalhamento dos solos}

A resistência ao cisalhamento de um solo saturado pode ser descrita pelas diversas combinações críticas da tensão normal efetiva com a tensão de cisalhamento. Essas combinações descrevem uma envoltória conhecida na mecânica dos solos como envoltória de ruptura de Mohr-Coulomb (GERSCOVICH, 2012).

\subsection{Atrito no Solo}

Segundo Fiori (2009), o conceito de atrito está fundamentalmente ligado ao movimento, pois o atrito surge quando se há a tendência ao movimento. Levando em conta que só há movimento por ação de forças, conclui-se que o atrito é a resistência ao movimento - uma força que se opõe à força provocadora de deslocamento.

O ângulo de atrito entre os sólidos, determinado por experimento usando o plano de cisalhamento, é conhecido como ângulo de atrito interno. Cada tipo de material apresenta o seu. $\mathrm{O}$ ângulo de atrito $(\varphi)$ é expresso como segue: 


$$
\frac{\tau}{\sigma}=\tan \Phi
$$

\subsection{Coesão}

No caso de solos considerados coesivos, há a presença de uma maior ligação entre as partículas, fazendo com que se exerça um esforço maior parar se efetuar o movimento. Isso levando em consideração que a coesão ou intercepto de coesão (c) é apenas uma resistência a mais que o material terá ao deslocamento, sempre fazendo analogia à mecânica dos sólidos. Desse modo, tem-se que a tensão cisalhante é expressa pela expressão a seguir:

$$
\tau=\mathrm{c}+\sigma \cdot \tan \Phi
$$

\subsection{Critério de Mohr-Coulomb}

Os critérios de rupturas procuram refletir as condições nas quais ocorre a ruptura dos materiais. O critério de MohrCoulomb é a mescla dos dois critérios que representam o comportamento dos solos: critérios de Coulomb e de Mohr. É assim justificado por utilizar uma reta que melhor se ajuste à envoltória de Mohr, semelhante à reta adotada por Coulomb para traçar a envoltória tangenciando os círculos de Mohr. A envoltória de Mohr-Coulomb delimita duas regiões no gráfico: os pontos situados abaixo da reta correspondem a estados de tensão antes da ruptura e, portanto, possíveis; os situados acima são impossíveis, pois o material terá rompido antes de alcançá-los (ORTIGÃO, 2007).

\subsection{Plano de Ruptura}

Caracteriza-se uma situação de ruptura iminente quando o círculo de Mohr tangencia a envoltória. O ponto de tangência define o plano de ruptura e as tensões sobre ele. A resistência ao cisalhamento do solo será igual à tensão cisalhante nesse ponto. $\mathrm{O}$ plano de ruptura faz um ângulo $\theta_{\mathrm{r}}$ com o plano principal maior e a tangente à envoltória no ponto de contato faz um ângulo $\varphi$ com o eixo das abscissas, como é esquematizado na Figura 6 (BASTOS, 2014).

Figura 6: Representação do plano de ruptura (BASTOS, 2014)

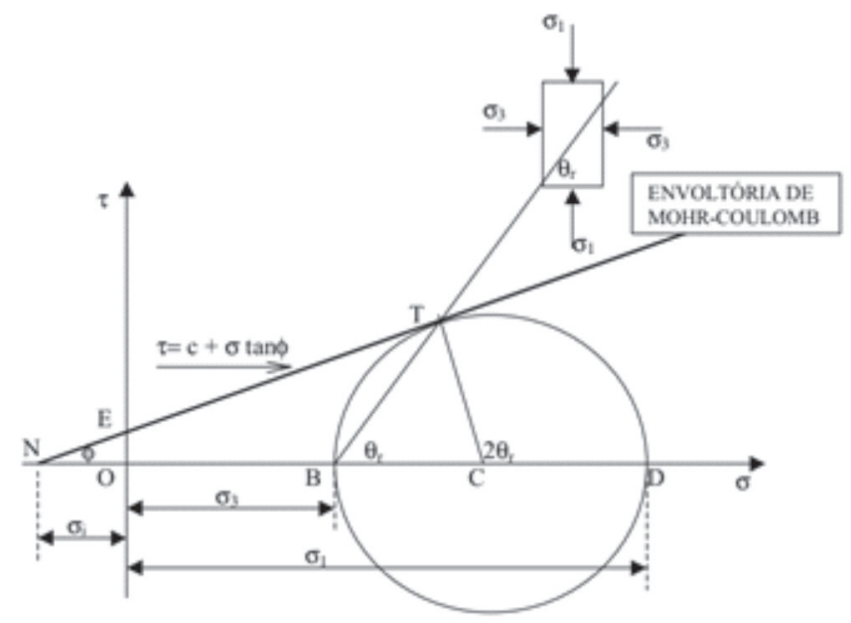

\subsection{Ensaios para determinação da resistência ao cisalhamento dos solos}

Costumeiramente, são empregados dois tipos de ensaios para a determinação da resistência ao cisalhamento dos solos: o ensaio de cisalhamento direto e o ensaio de compressão triaxial.

\subsection{Ensaio de cisalhamento direto}

De acordo com Pinto (2006), o ensaio de cisalhamento direto é o mais antigo procedimento para a determinação da resistência ao cisalhamento e se baseia diretamente no critério de Coulomb. Aplicando-se tensão normal num plano, verifica-se a tensão cisalhante que provoca a ruptura. Este ensaio não permite determinar parâmetros de deformabilidade 
do solo, porém, para a determinação da resistência - principalmente quando se deseja determinar a resistência residual -, torna-se o método mais útil, devido à sua simplicidade e praticidade.

\subsection{Ensaio de compressão triaxial}

Para Bastos (2014), o ensaio de compressão triaxial é o mais versátil para a determinação da resistência ao cisalhamento dos solos. Através do ensaio, podem-se obter parâmetros dos solos, tais como o ângulo de atrito e o intercepto de coesão. No ensaio, também é possível fazer a medição da poropressão, o que possibilita obter as tensões efetivas. O ensaio consiste na aplicação de um estado hidrostático de tensões e de um carregamento axial sobre um corpo de prova cilíndrico do solo. No ensaio triaxial, o corpo de prova é cilíndrico, com relação altura e diâmetro da ordem de 2. Em geral, os corpos de prova são moldados com diâmetros de 1,4", 2" e 4".

\subsection{Pressão confinante}

Segundo Head (1994), a pressão confinante utilizada no ensaio deve ser relacionada às condições de campo onde a amostra foi retirada. Não existem pressões confinantes padronizadas. Normalmente, quando uma amostra é ensaiada, são utilizados pelo menos três níveis de tensão: a tensão normal $\left(\sigma_{\mathrm{v}}\right)$, a metade da tensão normal $\left(0,5 \sigma_{\mathrm{v}}\right)$ e o dobro da tensão normal $\left(2 \sigma_{\mathrm{v}}\right)$. A faixa de pressões confinantes do aparelho triaxial deve cobrir a variação de pressões verticais que ocorrem no campo, ou seja, o equipamento deve ter a capacidade de reproduzir a situação decorrente do campo em laboratório.

\subsection{Tensão desviadora}

De acordo com Head (1994), o valor máximo de tensão desviadora tradicionalmente é associado com o rompimento de amostras de solos. É a condição máxima de diferença entre as tensões principais. Se as tensões principais totais verticais e horizontais são denominadas $\sigma_{1}$ e $\sigma_{3}$, respectivamente, a tensão desviadora é tida como $\left(\sigma_{1}-\sigma_{3}\right)$ durante o cisalhamento, e a deformação correspondente é representada por $\varepsilon$ na ruptura. Em um ensaio não drenado, a pressão neutra é denominada $u$, e a tensão principal efetiva no pico pode ser calculada.

Normalmente, dois tipos de situações são empregadas em ensaios de compressão triaxial: de deformação controlada e de tensão controlada, dependendo do tipo de equipamento disponível.

a) Ensaio de deformação controlada: impõem-se deformações e medem-se as tensões resultantes. Em geral, a velocidade de deformação é imposta por uma prensa. A base da amostra se movimenta ascendentemente, a uma velocidade constante, sendo o deslocamento do topo impedido. Com isso, mede-se a tensão desviadora. A vantagem desse esquema é que se pode reproduzir qualquer comportamento tensão x deformação, com ou sem pico bem definido.

b) Ensaio de tensão controlada: impõem-se tensões e medem-se as deformações resultantes. A vantagem desse esquema é poder reproduzir trajetórias de tensão diferentes das do ensaio de deformação controlada. Com isso, torna-se possível determinar parâmetros de deformabilidade adequados às trajetórias reais. Esses efeitos não atuam nos parâmetros da envoltória de resistência (envoltória única).

\subsection{Sobreadensamento}

Segundo Pinto (2006), quando a tensão confinante de ensaio é menor do que a tensão de pré-adensamento do solo, após a primeira etapa do ensaio, quando o corpo de prova é adensado sob tensão de confinamento, o solo se encontra sobreadensado. Quando a tensão confinante é muito menor do que a tensão de pré-adensamento, no ensaio CD, ocorre o aumento de volume durante o carregamento axial, o que provoca a entrada de água no corpo de prova. No ensaio CIU, não havendo drenagem, a água nos vazios do solo fica submetida a um estado de tensão de tração (da mesma maneira como ocorre numa seringa de injeção quando se puxa o pistão sem permitir a entrada de líquido). A Figura 9 mostra a expectativa do comportamento da pressão neutra no ensaio não drenado. 
Figura 7: Comportamento do carregamento axial não drenado de corpo de prova adensado a mesma tensão confinante, estando o solo muito sobreadensado (PINTO, 2006)

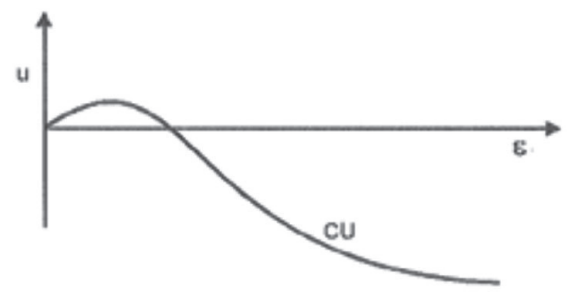

\subsection{Tipos de ensaios}

Dependendo das condições de drenagem, os ensaios podem ser classificados em três tipos:

\section{a) Ensaio adensado e drenado (CD ou CID)}

Conforme Gerscovich (2010), a drenagem é mantida aberta em todas as fases. Com isso, o ensaio permite que a amostra seja adensada para o nível de tensão efetiva desejado antes do cisalhamento e que a variação volumétrica seja monitorada. Isso pode ser feito facilmente em materiais saturados, bastando observar, através da bureta graduada, a quantidade de água que sai ou entra no corpo de prova.

\section{b) Ensaio adensado e não drenado (CU ou CIU)}

De acordo com Bastos (2014), a drenagem é permitida apenas na primeira etapa. Aplica-se $\sigma_{3}$, permitindo o adensamento, e depois $\sigma_{\mathrm{d}}$, sem drenagem. Na segunda etapa, as pressões neutras podem ser medidas. Podem ser obtidos parâmetros de resistência em termos de tensões totais e efetivas. O ensaio é empregado na análise de resistência ao cisalhamento solos de baixa permeabilidade adensados.

\section{c) Ensaio não adensado e não drenado (UU)}

Conforme Bastos (2014), a drenagem não é permitida em ambas as etapas. O teor de umidade da amostra mantém-se constante. As pressões neutras geradas podem ser medidas. Os parâmetros de resistência são obtidos em termos de tensões totais. O ensaio é empregado na análise de resistência ao cisalhamento solos de baixa permeabilidade não adensados.

\section{Metodologia}

Para a realização deste trabalho, foi feita a coleta da amostra com o intuito de executar os ensaios de compactação e os de caracterização do solo: densidade real do grão, análise granulométrica por peneiramento e sedimentação, e ensaios de limites de consistência do solo. Foram realizados ensaios de compressão triaxial, do tipo CIU, efetuando um estudo comparativo do efeito da dimensão de diferentes diâmetros em solos arenosos. Foram fornecidos os parâmetros de resistência ao cisalhamento para os corpos de prova de 1,4" e 2" de diâmetro. Executou-se um total de 21 ensaios, dos quais 8 com os corpos de prova de diâmetro 2" e 13 com o de 1,4" de diâmetro, para a obtenção de resultados satisfatórios.

\section{Resultados e Discussões}

Serão apresentados nesta seção resultados encontrados a partir dos ensaios de caracterização do solo e traxial referentes a três corpos de prova de cada diâmetro - 1,4" e 2" -, apresentando resultados de acordo com os $\sigma_{3}$ aplicados, podendo gerar os círculos de Mohr e se obter as envoltórias de Mohr-Coulomb, seus respectivos parâmetros e a análise dos planos de ruptura dos corpos de prova.

\subsection{Ensaios de Caracterização}

Por meio dos ensaios de caracterização através de sua granulometria, mostrada na Tabela 1, pode-se identificar a amostra, a partir do sistema do SUCS (Sistema Unificado de Classificação dos solos), como SW-SC, ou seja, uma areia argilosa bem graduada. Na classificação TRB (Transportation Research Board), o solo é qualificado como A-2-4, que é um solo composto de finos siltosos de baixa compressibilidade. 
Tabela 1: Resumo da granulometria

\begin{tabular}{c|c|c}
\hline Tipo de solos & Diâmetro das partículas & Porcentagem que passa \\
\hline Pedregulho & $>4,8 \mathrm{~mm}$ & $0 \%$ \\
Areia grossa & $4,8-2,0 \mathrm{~mm}$ & $0 \%$ \\
Areia média & $2,0-0,42 \mathrm{~mm}$ & $0 \%$ \\
Areia fina & $0,42-0,05 \mathrm{~mm}$ & $83 \%$ \\
Silte & $0,05-0,005 \mathrm{~mm}$ & $3 \%$ \\
Argila & $0,005 \mathrm{~mm}>$ & $14 \%$ \\
\hline TOTAL & & $100 \%$ \\
\hline
\end{tabular}

Fonte: MONTEIRO, 2014

\subsection{Ensaio de Compactação}

Com o ensaio de compactação, foi verificada umidade ótima de 10,5\% e peso específico seco máximo de 19,17 kN/ $\mathrm{m}^{3}$.

\subsection{Círculos de Mohr}

Com os ensaios de compressão triaxial, foi obtida a envoltória de Mohr-Coulomb, assim achando os parâmetros de resistência do solo: o intercepto de coesão e o ângulo de atrito interno. Neste item, são mostrados os círculos de Mohr obtidos e os respectivos parâmetros.

a) Corpos de prova de 2 "

A Tabela 2 contém as tensões principais totais, efetivas, pressões neutras correspondentes aos corpos de prova de 2" e os raios dos círculos de Mohr (R).

Tabela 2: Tensões principais para CP de 2"

\begin{tabular}{c|c|c|c|c|c|c}
\hline $\mathbf{N}^{\mathbf{0}} \mathbf{d o} \mathbf{C P}$ & $\sigma_{\mathbf{3}}(\mathbf{k P a})$ & $\sigma_{\mathbf{1}}(\mathbf{k P a})$ & $\mathbf{R}(\mathbf{k P a})$ & $\mathrm{u}(\mathrm{kPa})$ & $\left.\sigma_{\mathbf{}_{1}} \mathbf{k P a}\right)$ & $\sigma_{3}(\mathbf{k P a})$ \\
\hline 3 & 100 & 812 & 356 & -163 & 975 & 263 \\
24 & 200 & 100,4 & 402 & -110 & 111,4 & 310 \\
4 & 300 & 144,3 & 572 & -139 & 158,2 & 439 \\
\hline
\end{tabular}

Fonte: Monteiro, 2014.

Na Figura 8, a envoltória de Mohr-Coulomb é apresentada considerando tensões totais, de forma que é possível verificar os parâmetros do solo, c=1,19 e $\phi=32,2^{\circ}$.

Figura 8: Envoltória com tensões totais dos corpos de prova de 2"

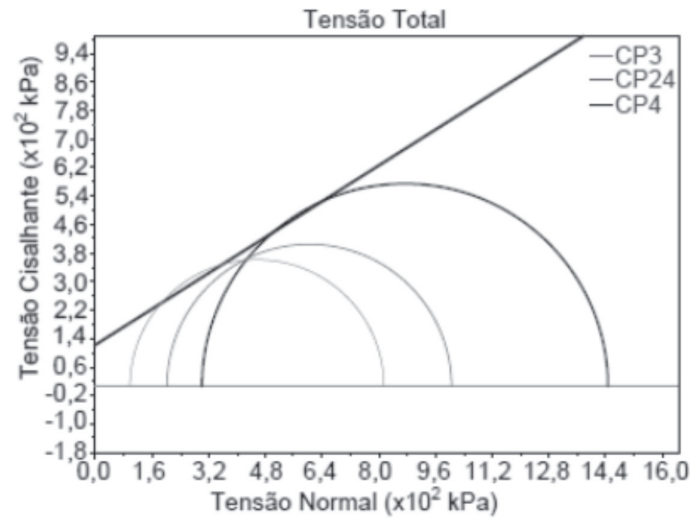


A partir das tensões efetivas e dos círculos de Mohr, são determinados os parâmetros do solo. A partir da Figura 9 , pode-se concluir que o intercepto de coesão efetiva $\left(c^{\prime}\right)=0,12$ e o ângulo de atrito efetivo $\left.(\phi\rangle\right)=33,72^{\circ}$.

Figura 9: Envoltória com tensões efetivas dos corpos de prova de 2"

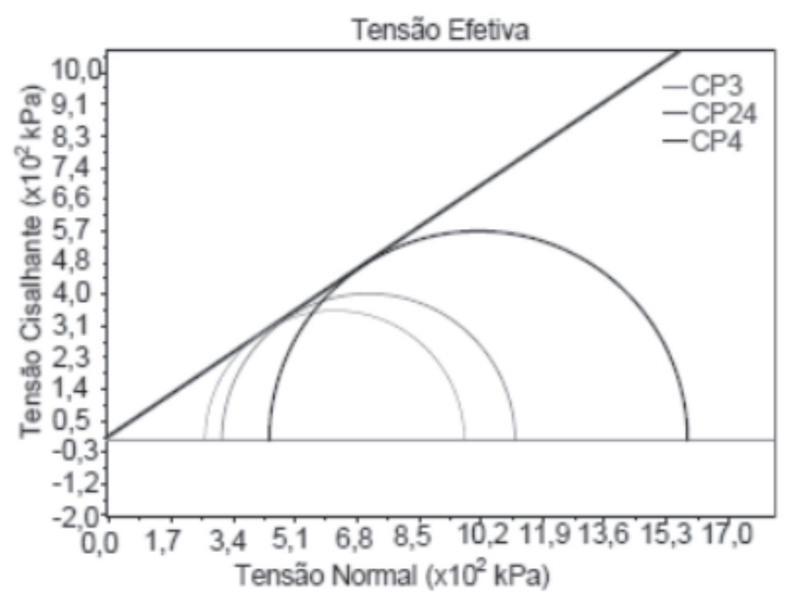

b) Corpos de prova de 1,4"

A Tabela 3 apresenta as tensões principais totais, efetivas e poropressões correspondentes aos corpos de prova de 1,4" e raios dos círculos de Mohr (R).

Tabela 3: Tensões principais para CP de 1,4"

\begin{tabular}{c|c|c|c|c|c|c}
\hline $\mathbf{N}^{\mathbf{0}} \mathbf{d o} \mathbf{C P}$ & $\sigma_{\mathbf{3}}(\mathbf{k P a})$ & $\sigma_{\mathbf{1}}(\mathbf{k P a})$ & $\mathbf{R}(\mathbf{k P a})$ & $\mathbf{u}(\mathbf{k P a})$ & $\sigma_{\mathbf{1}}(\mathbf{k P a})$ & $\sigma_{\mathbf{}_{\mathbf{3}}}(\mathbf{k P a})$ \\
\hline 17 & 100 & 495 & 198 & -109 & 604 & 209 \\
18 & 200 & 934 & 367 & -70 & 100,4 & 270 \\
22 & 300 & 127,3 & 487 & -78 & 135,1 & 378 \\
\hline
\end{tabular}

Fonte: (MONTEIRO, 2014)

A envoltória de Mohr-Coulomb é apresentada na Figura 13, considerando tensões totais, tendo-se que $\mathrm{c}=0,3$ e $\phi=$ $36,35^{\circ}$.

Figura 10: Envoltória com tensões totais dos corpos de prova de 1,4"

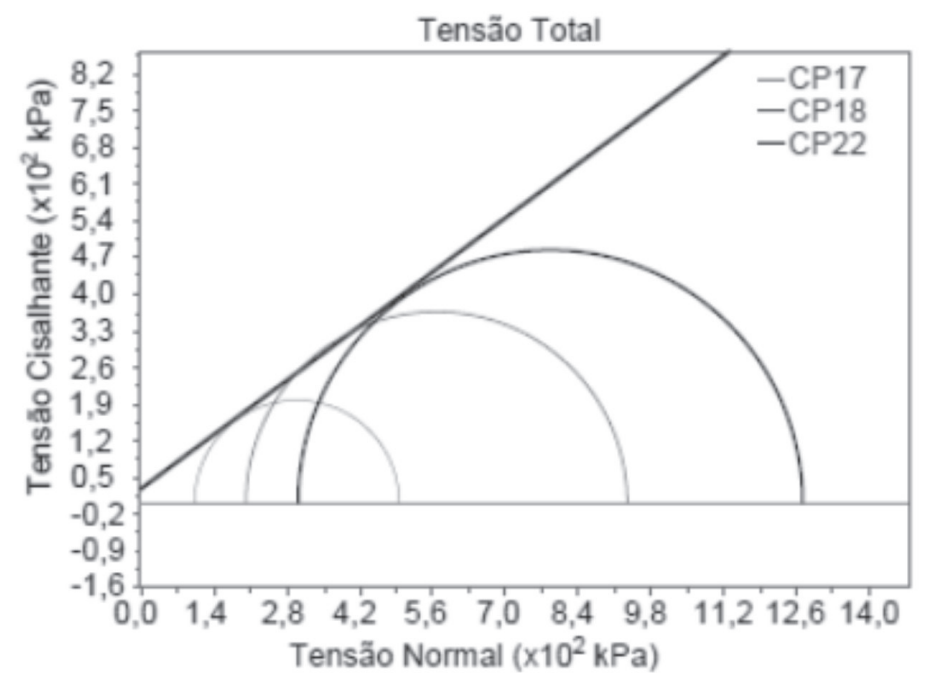


A Figura 11 mostra a envoltória de Mohr-Coulomb para tensões efetivas, e os parâmetros de resistência do solo obtidos são: $c^{\prime}=-66$ e $\phi>=39,16^{\circ}$.

Figura 11: Envoltória com tensões efetivas dos corpos de prova de 1,4"

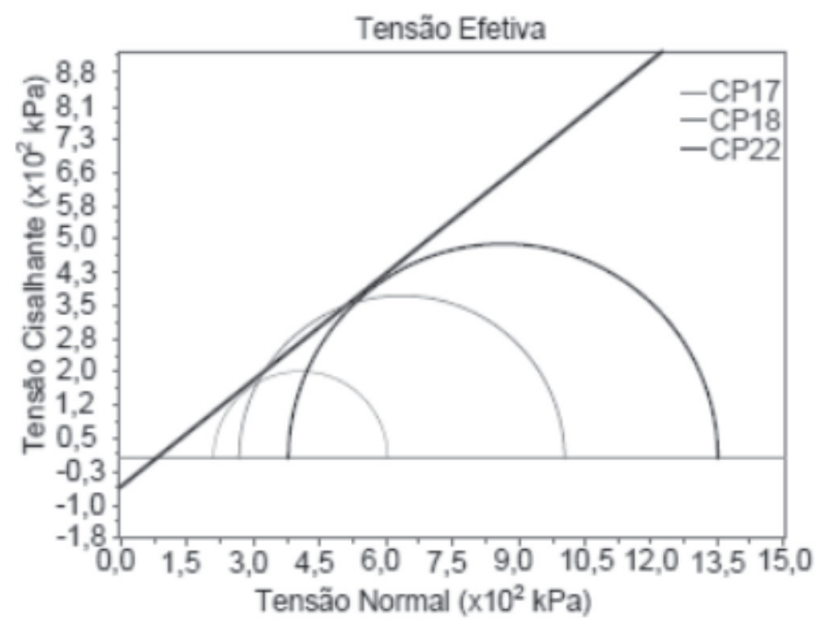

\subsection{Plano de ruptura para os corpos de prova de 2"}

A partir do resultado do ensaio, considerando as tensões efetivas e corpos de prove de 2" de diâmetro, foi traçada uma reta partindo de $\sigma_{3}$ até o ponto em que a envoltória de Mohr-Coulomb tangencia o círculo de Mohr. O ângulo formado entre o plano principal maior, eixo das abscissas, e a referida reta equivale ao ângulo do plano de ruptura, como é detalhado na Figura 15.

Figura 12: Plano de ruptura no corpo de prova de 2"

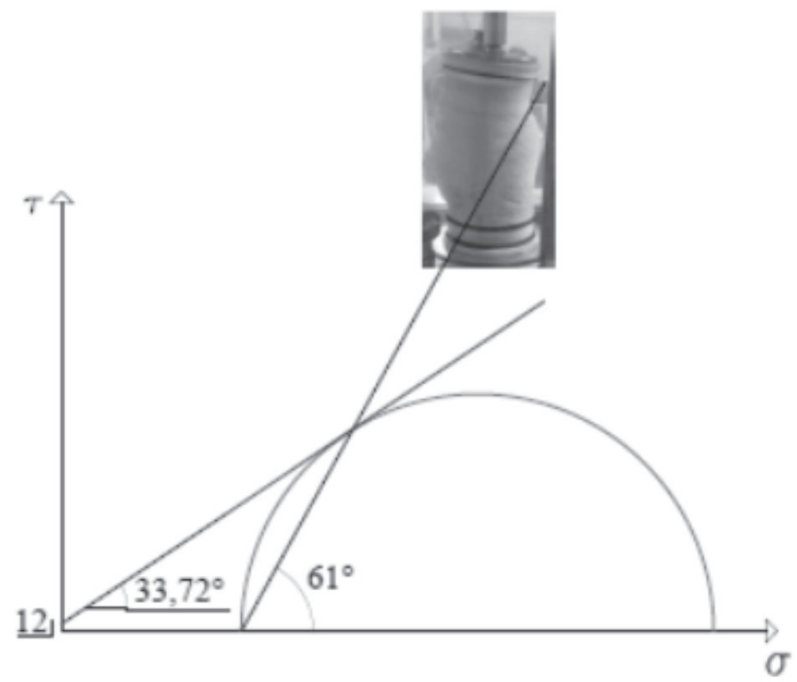

A partir da Figura 12, podemos averiguar que o ângulo de ruptura para os corpos de prova de 2" é de $61^{\circ}$.

\subsection{Plano de ruptura para os corpos de prova de 1,4"}

No corpo de prova de 1,4", após traçarmos a linha da tensão principal menor até o ponto de tangência, é visto que o ângulo de ruptura é de $63^{\circ}$, como detalhado na Figura 16. 
Figura 13: Plano de ruptura no corpo de prova de 1,4"

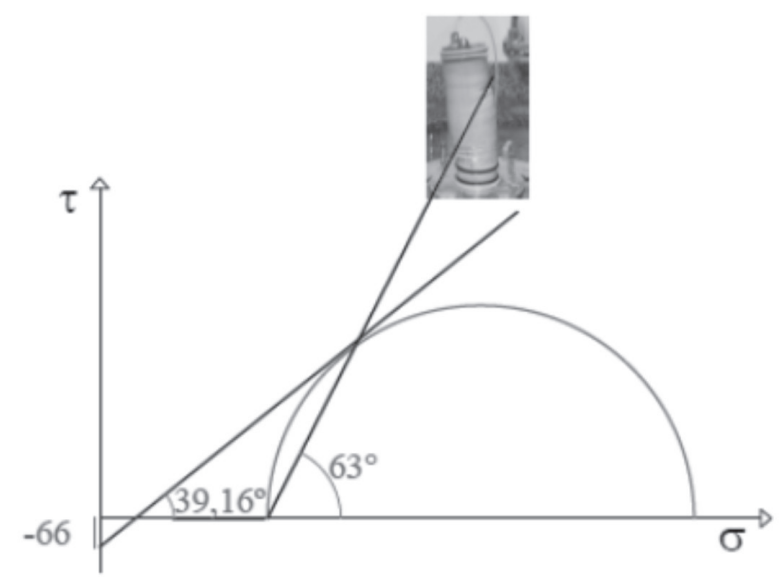

\subsection{Comparação entre os resultados dos corpos de prova de 2" e 1,4"}

Na Tabela 4, é feita a comparação dos resultados entre os corpos de prova de tamanho diferentes.

Tabela 4: Comparação dos resultados

\begin{tabular}{c|c|c|c|c|c}
\hline $\mathbf{C P}$ & $\mathbf{C ~ ( k P a )}$ & $\phi\left(^{(}\right)$ & $\left.\mathbf{C}^{\boldsymbol{}} \mathbf{( k P a}\right)$ & $\phi>\left(^{\circ}\right)$ & $\phi \mathrm{r}\left({ }^{\circ}\right)$ \\
\hline $1,4 ”$ & 30 & 36,35 & -66 & 39,16 & 63 \\
$2{ }^{\prime \prime}$ & 119 & 32,2 & 12 & 33,72 & 61 \\
\hline
\end{tabular}

Fonte: MONTEIRO, 2014

A partir da tabela, pode-se analisar que não houve uma grande variação nos ângulos de atrito totais e efetivos, e do ângulo de ruptura. Quanto à coesão, existe uma diferença razoável.

\section{Conclusão}

Por meio dos ensaios de compressão triaxial, pode-se obter os círculos de Mohr totais e efetivos para as suas pressões confinantes correspondentes de $100 \mathrm{kPa}, 200 \mathrm{kPa}$ e $300 \mathrm{kPa}$. A partir do círculo de Mohr, é possível traçar a envoltória de Mohr-Coulomb, a partir da qual é possível estimar os parâmetros totais e efetivos de resistência ao cisalhamento para corpos de provas de diferentes dimensões: o intercepto de coesão e o ângulo de atrito interno do solo. Com relação aos parâmetros efetivos, foram obtidos para os corpos de prova de diâmetros 1,4" e 2" os ângulos de atrito, respectivamente, $39,16^{\circ}$ e $33,72^{\circ}$, e interceptos de coesão $-66 \mathrm{kPa}$ e $12 \mathrm{kPa}$, havendo uma diferença de $13,89 \%$ entre os ângulos mencionados.

Com relação aos interceptos de coesão, os diâmetros apresentaram uma variação de $81,81 \%$ entre as respectivas coesões. Verificou-se uma coesão efetiva negativa para o corpo de prova de 1,4" de diâmetro, justificado pelo fato de o material apresentar valores de coesão muito baixos e por um pequeno desvio na envoltória, o que pode indicar valores negativos, apesar de baixos. Quanto aos ângulos de ruptura, o corpo de prova de 2" de diâmetro indicou um ângulo de $61^{\circ}$; e o de 1,4 " de diâmetro, um ângulo de $63^{\circ}$, apresentando uma variação pouco significativa.

Para Pinto (2006), as areias bem graduadas de grãos arredondados apresentam ângulos de atrito com valores compreendidos entre $30^{\circ}$ e $40^{\circ}$. Desse modo, mesmo com os valores apresentando uma diferença significativa em relação à coesão, pode-se afirmar que não há grande discrepância entre os resultados, pois os ângulos de atrito dos corpos de prova de 2" e 1,4" estão compreendidos nesse intervalo determinado para a mesma classificação.

Para a realização do ensaio, os procedimentos são idênticos, com algumas pequenas diferenças, como na quantidade de solo utilizado para os corpos de prova de 2" (em média $500 \mathrm{~g}$ ) e de 1,4” (em média $200 \mathrm{~g}$ ). Durante os ensaios, foram verificadas algumas dificuldades para a realização dos procedimentos nos corpos de prova de 1,4" de diâmetro, 
Análise comparativa de resultados de ensaios de compressão triaxial com corpos de prova de diferentes dimensões

principalmente na compactação, aplicação da membrana e dos anéis de borracha. Para conclusões mais específicas e confirmação dos parâmetros obtidos, recomenda-se a realização de ensaio comparativo com maior número de amostras.

\section{Referências}

BASTOS, C. Resistência ao cisalhamento dos solos. Universidade Federal do Rio Grande. 2014. Disponível em: <fttp://ftp.cefetes.br/cursos/Transportes/CelioDavilla/Solos/Literatura\%20complementar/Apostila\%20FURG\%20 Solos/14-\%20RESISTENCIA.pdf $>$. Acesso em: 21 jan. 2015.

BISHOP, A. W.; HENKEL, D. J. The measurement of soil properties in the triaxial test. 2. end. Londres, UK: Edward Arnold Ltd., 227 p. 1962.

CAPUTO, H. P. Mecânica dos solos e suas aplicações. 6. ed. Rio de Janeiro: Livros Técnicos e Científicos, 1988.

FIORI, A. P.; CARMIGNANI, L. Fundamentos de mecânica dos solos e das rochas: aplicações na estabilidade de taludes. 2 ed. rev. e ampl. Curitiba: Ed. UFPR, 2009.

GERSCOVICH, D. M. S. Tensões em solos. Universidade do Estado do Rio de Janeiro. Rio de Janeiro, 2008.

Disponível em: $<\mathrm{http} / /$ www.eng.uerj.br/ denise/pdf/tensoes.pdf $>$. Acesso em: 21 jan, 2015.

GERSCOVICH, D. M. S. Resistência ao cisalhamento. Universidade do Estado do Rio de Janeiro. Rio de Janeiro, 2010. Disponível em: <http://www.eng.uerj.br/ denise/pdf/resistenciacisalhamento.pdf $>$. Acesso em: 21 jan. 2015.

GERSCOVICH, D. M. S. Estabilidade de taludes. São Paulo: Oficina de Textos, 2012.

HEAD, K. H. Manual of soil laboratory testing. Chichester: John Wiley \& Sons, 1994. 2 v.

HEAD, K. H. Manual of soil laboratory testing. Chichester: John Wiley \& Sons, 1994. 3 v.

ORTIGÃO, J. A. R. Mecânica dos solos dos estados críticos. 3.ed. Rio de Janeiro: Terratek, 2007.

PINTO, C. de S. Curso básico de mecânica dos solos. 3.ed. São Paulo: Oficina de Textos, 2006.

MONTEIRO, F. F. Avaliação do efeito da dimensão em ensaios triaxiais em solos arenosos. 2014. 49 f. Trabalho de Conclusão de Curso (Bacharelado em Engenharia Civil) - Centro de Ciências Tecnológicas, Universidade de Fortaleza, Fortaleza, 2014.

TERZAGHI, K. The shear resistence of saturated soils. Proc. First International Conference on Soil Mechanics \& Fundation Engineering, Cambridge, MA, 1:54-56, 1936.

Sobre os autores

\section{Icaro Rodrigues Marques}

Graduando em engenharia civil, Universidade de Fortaleza - UNIFOR. Graduando em Tecnologia em Estradas - IFCE.

\section{Fernando Feitosa Monteiro}

Mestrando em engenheiro civil, área de concentração geotecnia, pela Universidade Federal do Ceará - UFC, graduado em engenharia civil pela Universidade de Fortaleza (2014).

\section{Marcos Fábio Porto de Aguiar}

Doutor em engenharia civil, área de concentração geotecnia, pela COPPE/Universidade Federal do Rio de Janeiro (2008), Mestre em geotecnia e Infraestrutura pela Universidade de Hannover- Alemanha (1997) e graduado em engenharia civil pela Universidade Federal do Ceará (1993), Professor da Universidade de Fortaleza (UNIFOR) e Instituto Federal do Ceará (IFCE). Consultor na área de fundações, contenções e infraestrutura de transporte.

\section{Francisco Heber Lacerda de Oliveira}

Doutorando e em engenharia civil, área de concentração engenharia de transportes, pela Universidade Federal do Ceara, Mestre em engenharia de transportes pela Universidade Federal do Ceará (2009), Professor da Universidade de Fortaleza (UNIFOR). Consultor em engenharia de transportes. 